\title{
Humanizing Indigenous Peoples' engagement in health care
}

— Cite as: CMAJ 2020 January 20;192:E70-2. doi: 10.1503/cmaj.190754

\section{Two-Eyed Seeing}

$\square$ tuaptmumk, "Two-Eyed Seeing" in Mi'kmaq, integrates the strengths of Indigenous and Western knowledge as a shared-learning process attributed to Albert Marshall, Mi'kmaw Elder of Mi'kma'ki, who developed this concept. Mi'kma'ki is the Mi'kmaw traditional territory in the Atlantic provinces, Gaspé and Maine.

Mi'kmaw perspectives for care originate from Mi'kmaw Seven Sacred Teachings of love, honesty, humility, respect, truth, patience and wisdom, ${ }^{1}$ which are transferable ethical values for health care. Mandating emotions, like love, is unheard of in Western-based clinical care, but Indigenous perspectives in health care teach about honesty, humility and respect as positive behaviours to help build trust, relationships and safe spaces. ${ }^{2}$

Traditionally, Western-based knowledge in health is "predominantly shaped by conventional scientific approaches,"3 vigorously clinical and data driven. It may question the credibility of nonclinical approaches, conveying the principle that "anything that falls outside of scientific reasoning is disregarded as inconclusive."3 Marie Battiste, Mi'kmaw scholar, describes this dismissive stance as "cognitive manipulation," which she terms "cognitive imperialism." Frequently, Indigenous knowledge is viewed as mystical and traditional, yet Battiste affirms that it "is a complete knowledge system ... of concepts of epistemology, philosophy, language, scientific and logical validation." 4 Two-Eyed Seeing implements the strengths of both knowledge systems to address contemporary needs of Indigenous people's health. It incorporates the understanding of the relational as a collec-

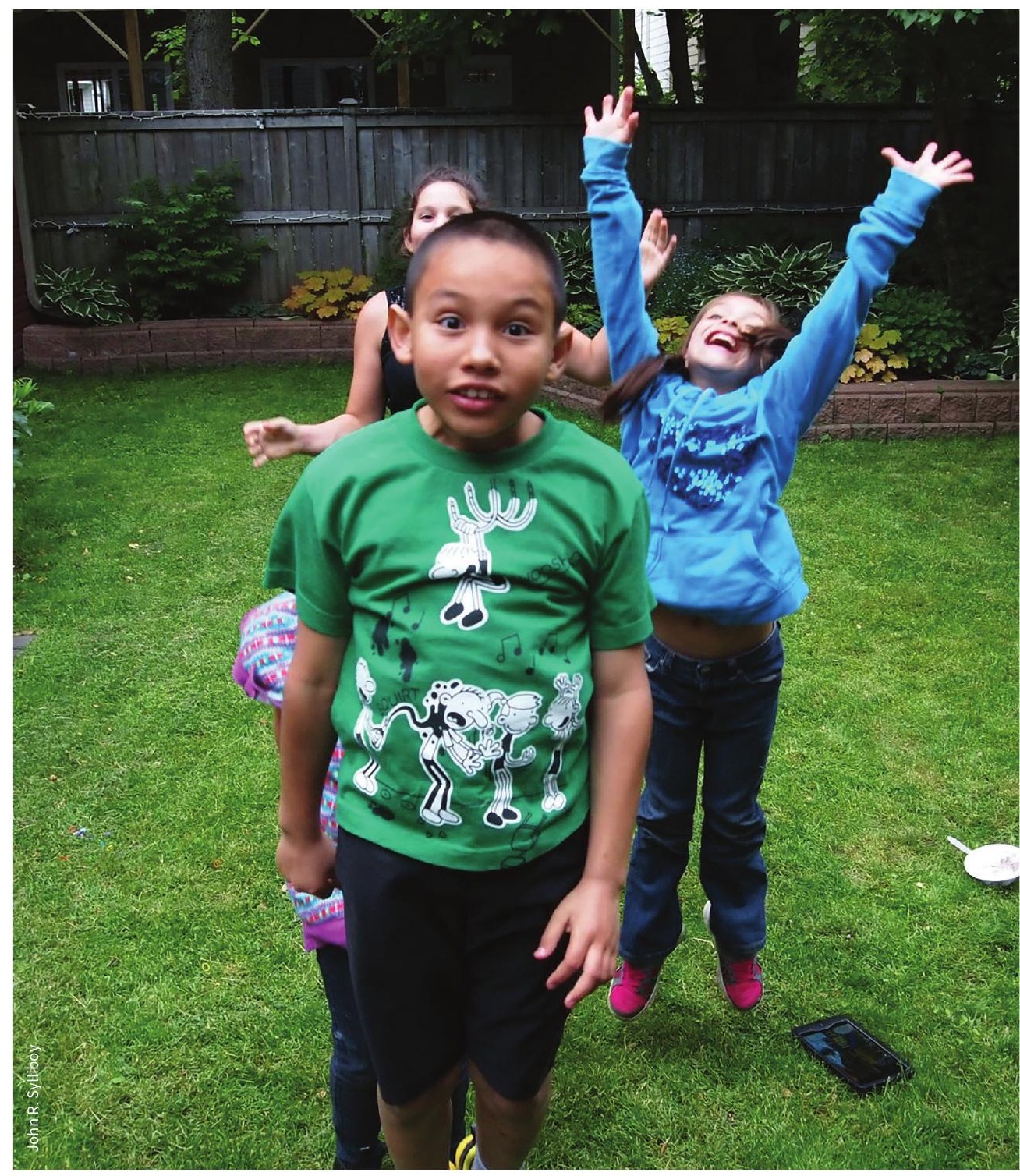

Almi'jka'tijik: "They are playing” in Mi'kmaq. Front to back: Corey Dennis, Dakiya Nelson, Elle Taylor Gould and Daijah Nelson.

tive value of kinship based on respect and love, deeply embedded in cultural knowledge and the Mi'kmaw worldview.

Learning through nurturing positive relationships encourages trust in other people who may be unfamiliar to us: we become vulnerable in the presence of the other, to open up to them, to learn, trust and care. Trust can also be an action, meaning to place confidence in someone's qualities, 
fairness, truth and professional ability. In essence, trusting is the confidence in a person to do the right thing, take the right action, be what they purport to be, and be aware of how others interact through their cultural norms and practices. ${ }^{5}$ Indigenous children will be more trusting of clinicians whose practice is guided by this approach.

\section{Relearning to listen}

Dr. Janet Smylie, a Métis physician, has shared that if the health care system embraces Indigenous perspectives, Indigenous health and community outcomes will benefit:

Indigenous epistemologies, ... intrinsically connect knowledge with action.... In this way, knowledge development work is actively transformative as it is linked to life-long process of human development. Stories themselves can be perceived as holding "medicine" and the act of sharing stories as acts of healing. ${ }^{6}$

Elder Marshall collaborated on the Aboriginal Children's Hurt and Healing Initiative study, in an attempt to invoke 2 sets of lenses or perspectives within a sharedlearning process, to improve patient engagement. In this study, ${ }^{7}$ Indigenous and non-Indigenous clinicians amassed knowledge and experiences based on their interactions with Indigenous patients, and then offering recommendations to humanize Indigenous Peoples' health care engagement.

This research team contextualized their recommendations into a set of culturally specific practices that enhance cultural safety in clinical health care for Indigenous children and youth who suffer from pain. Indigenous people often seek primary care as outpatients, but it is also where Indigenous people feel most vulnerable, owing to racism and fear of stigmatization for seeking pain care. ${ }^{7}$

The acronym FIRST means an approach that comprises Family (recognizing the extended family of a patient), Information (communication that is respectful), Relationship (building positive relationships), Safe Space (understanding cultural safety) and Treatment (providing options for treatment, both traditional medicine and standard clinical treatment). ${ }^{2}$ Combining Indigenous knowledge (community-based experiences and practices) with Western (clinical) knowledge produced the "FIRST" approach.

The implementation of FIRST enhances communication during health care interactions, increasing the likelihood of an accurate diagnosis. For example, clinicians could implement the FIRST method with standard clinical practices (pain scale, facial grimaces) within a Two-Eyed Seeing approach that would improve Indigenous Peoples' engagement in health care.

Marshall's wisdom conveys a message of a continuous negotiation and collaboration between 2 knowledge systems; co-existing, without compromising the strengths of each. Yet, Elder Albert underscored the importance of not compromising the essence of the Mi'kmaq:

Two-Eyed Seeing is inherent in the Mi'kmaw way of thinking. I think it's imperative that we apply those lessons learned from our forefathers, as to how do we weave back and forth in these 2 worlds in which we have to co-exist without compromising the essence of who you are as a Mi'kmaq. ${ }^{8}$ how Indigenous children may share their pain or hurt through stories, which may require additional time while encouraging positive relationship growth.

Integrating the FIRST principle is continuous and interwoven throughout relationship development. If a physician assumes coleadership in building trusting relationships, it will enhance present and future engagements. Continuous engagement means the implementation of Mi'kmaw cultural teachings of truth, honesty and patience as core to building healthy relationships. Elder Murdena Marshall explains, "gifts must be visible"1 to be healers. Physicians are healers, and they acquired their gifts of knowledge through extensive training, research and practice, like Elders in their quest for wisdom. Indigenous children learn through tribal consciousness, which is why the story is a compelling way of communicating. ${ }^{4,9}$ Children develop a keen sense of nonverbal communication through unspoken words, gestures and body language,

\section{Mi' kmaw perspectives for care originate from Seven Sacred Teachings of love, honesty, humility, respect, truth, patience and wisdom, which are transferable ethical values for health care}

The Mi'kmaw Sacred Teachings and Elder Albert's Two-Eyed Seeing wisdom are the foundations of the FIRST approach. It stresses the need for clinicians to apply a relational approach in health care. If adequate time and space is administered for listening to learn through the FIRST approach, clinicians may find themselves expanding their habituated discipline-specific ways of knowing and understanding.

Two-Eyed Seeing guides us toward a relational way of being, ${ }^{5}$ listening and learning from what children say about their health, for example. ${ }^{7}$ It is critical that clinicians comprehend the complexity of which are all part of oral and nonoral traditions. ${ }^{4}$ The importance of the relational aspects of clinical care is that it enhances information-sharing through culturally relevant communication. It is not meant to presume that physicians act as Indigenous people; instead, it means to provide knowledge and cultural awareness such that physicians understand the value of Two-Eyed Seeing in their practice. ${ }^{10}$

Currently, within Canadian health care, Indigenous people may feel stigmatized because of deficit-based discourses in relation to Indigenous health inequalities. ${ }^{7}$ Two-Eyed Seeing expands and demystifies 
Indigenous knowledge with other knowledge systems, which can translate into collaborative approaches for Indigenous health and well-being. The FIRST approach empowers clinicians as agents of transformative change to enhance health care encounters with Indigenous people. The FIRST approach is currently embedded in the curriculum of Dalhousie University's first-year education for health professionals. Two-Eyed Seeing expands knowledge and new perspectives ${ }^{9}$ to improve health care for all Indigenous Peoples.

\section{John R. Sylliboy MA}

Aboriginal Children's Hurt and Healing Initiative, Centre for Pediatric Pain

Research, IWK Health Centre, Halifax, NS

Richard B. Hovey PhD

Faculty of Dentistry, Division of Oral Health \& Society, McGill University, Montréal, Que.

\section{References}

1. The Atlantic Aboriginal Economic Development Integrated Research Program. APCFNC Elders Project - honouring traditional knowledge. Dartmouth (NS): Atlantic Policy Congress of First Nations Chiefs (APCFNC) Secretariat; 2014.

2. The FIRST Approach. Aboriginal Children's Hurt and Healing Initiative (ACHH); 2017. Available: https://achh.ca/knowledge-research/our-progress/ (accessed 2019 Oct. 21)

3. Martin DH. Two-eyed seeing: a framework for understanding indigenous and non-indigenous approaches to indigenous health research. Can J Nurs Res 2012;44:20-42.

4. Battiste M. Maintaining aboriginal identity, language, and culture in modern society. In: Reclaiming Indigenous voice and vision. Vancouver: UBC Press; 2009.

5. Hovey RB, Delormier T, McComber AM, et al. Enhancing Indigenous health promotion research through two-eyed seeing: a hermeneutic relational process. Qual Health Res 2017;27:1278-87.

6. Smylie J, Olding M, Ziegler C. Sharing what we know about living a good life: Indigenous approaches to knowledge translation. J Can Health Libr Assoc 2014;35:16-23.
7. Latimer M, Sylliboy JR, MacLeod E, et al. Creating a safe space for First Nations youth to share their pain. Pain Rep 2018;3(Suppl 1):e682.

8. $\mathrm{ACHH}$ video: Two-Eyed Seeing approach $[\mathrm{ACHH}$ video]. Stony Plain (AB): Alberta Community Council on HIV (ACHH) Initiative; 2018. Available: https://achh.ca/about-us/our-approach-two-eyed -seeing/ (accessed 2019 Oct. 21).

9. Bartlett C, Marshall M, Marshall A. Two-Eyed Seeing and other leassons learned within a colearning journey of bringing together Indigenous and mainstream ways of knowing. J Environ Stud Sci 2012;2:231-40. doi: 10.1007/ s13412-012-0086-8.

10. Hall L, Dell CA, Fornssler B, et al. Research as cultural renewal: applying two-eyed seeing in a research project about cultural interventions in First Nations addictions treatment. Int Indig Policy J 6:1-15.

This article was solicited and has been peer reviewed.

Consent was received from the parents of the children depicted in the photo.

Competing interests: None declared. 